\title{
Práticas de Pesquisa em Educação Ambiental em Diferentes Espaços Institucionais Educação Ambiental em Portugal: Investigação Sobre as Práticas
}

\author{
Cecília Galvão \\ Centro de Investigação em Educação da Faculdade de Ciências da \\ Universidade de Lisboa
}

Resumo: A Educação Ambiental teve a sua expansão em Portugal a partir de uma proposta da UNESCO, em 1984/85, tendo envolvido vários Ministérios, Associações de protecção da natureza e escolas básicas e secundárias. Surgiu assim o projecto de Educação Ambiental para o Desenvolvimento, firmado em protocolos entre várias entidades como a Direcção Geral do Ensino Básico e Secundário e o Instituto Nacional do Ambiente, definindo-se a Educação Ambiental enquanto processo de formação orientada para a resolução de problemas, de uma forma interdisciplinar, de modo a integrar-se na comunidade e ter um carácter de educação permanente. Várias experiências foram desenvolvidas nas escolas, por vezes em ligação a universidades, e surgiram linhas de investigação com o objectivo de tornar visíveis essas experiências como exemplo de boas práticas educativas. Nesta comunicação, apresentaremos algumas dessas linhas metodológicas como os estudos de caso, os estudos etnográficos e a narrativa como as que apresentam grandes potencialidades na área de Educação Ambiental. Serão dados alguns exemplos de estudos realizados com professores em Portugal, de modo a tornar mais explícita a importância desses métodos de investigação. Tornar visíveis as experiências inovadoras é um dos melhores caminhos para contagiar para o envolvimento em projectos que se pretende constituam não apenas momentos na vida de alguém, mas, sobretudo, constituam mudanças de atitude para toda uma vida. Há hoje a noção de que para criar qualidade de vida, no sentido pessoal e colectivo, é indispensável a participação de todos, mas numa 
perspectiva ecocêntrica e não antropocêntrica. Alertar as crianças e os jovens para a importância do seu comportamento e intervenção na gestão dos recursos, torná-los sensíveis ao que se passa à sua volta, aprendendo a discutir e a dar argumentos que fundamentem a sua opinião, é educar para o ambiente e a sustentabilidade. Daí a importância de os currículos escolares incluírem estas problemáticas. Como professores e investigadores, temos uma grande responsabilidade, educar, tornando visível o que se faz para mostrar que é possível fazer mais e melhor, mas, sobretudo, despertar consciências para que os próprios alterem comportamentos indesejados.

Palavras-chave: Educação Ambiental. Etnografia. Narrativa

Abstract: The follow-up of an UNESCO proposal was by 1984/85 the starting point for the development of studies on Environmental Education in Portugal. A movement involving ministries, environmental organizations and secondary schools set up a project called Environmental Education for the Development based on protocols among institutions which assumed that Environmental Education is an interdisciplinary process that can help resolution of community problems and it is a long life learning process. Several projects were started at school level, often in connection with universities, and at the same time also some research projects were developed in order to enhance those experiences as good educational practices. In this paper we will introduce some of those research perspectives, like case study, ethnographic study and narrative. To clarify these perspectives, some examples of studies developed with teachers in Portugal will be given. Promoting the innovative experiences is the best way to involve teachers and students in Environmental Education, in order to change attitudes for life. Today we think that quality of life means a collective participation and the engagement on earth sustainability, with an ecocentric view, in opposition to an anthropocentric one. That's one of the reasons that curricula should include these items. To make students aware of the importance of their behaviour on the management of resources, as well as observant and sensitive to the environment, at the same time learning how to discuss and argue on defence of their own opinions, is part of a process towards education for environment and sustainability. This is of major responsibility for teachers as educators. The message is to awake the consciences to change persons' undesirable behaviours.

Keywords: Environmental Education. Ethnography. Narrative. 


\section{Introdução}

O conceito de Educação Ambiental (EA) é relativamente recente, tem pouco mais de trinta anos, e foi evoluindo, desde as conferências promovidas pela Unesco, realizadas em Belgrado em 1975 e em Tbilissi, em 1977, de acordo com uma consciência cada vez mais colectiva de intervenção positiva na natureza (UNESCO, 1989). A EA começou por assumir um carácter naturalista, ingénuo, de elogio de regresso ao passado e recusa do progresso, visto como intrinsecamente antiambiental. $O$ conceito foi evoluindo no sentido de assumir características de maior realismo, pensando o futuro com outra lógica de desenvolvimento e de progresso, tomando hoje, cada vez mais, a designação de desenvolvimento sustentável (integrando as perspectivas económica, social, política e ética). Implicitamente, estão presentes práticas de participação, de projecto, de interdisciplinaridade, construídas tendo por base outros conceitos como complexidade, reflexão, criatividade e diversidade. Mas ainda hoje não é difícil encontrar visões antropocêntricas de defesa do ambiente, embora tenham mais expressão as biocêntricas e as ecocêntricas (ALMEIDA, 2005).

O projecto de Educação Ambiental para o Desenvolvimento iniciou-se em Portugal a partir de uma proposta da UNESCO. Em 1984/85, envolveu o então existente Ministério da Qualidade de Vida através do Serviço Nacional de Parques, Reservas e Conservação da Natureza (SNPRCN) e a Direcção Geral do Ensino Básico e Secundário (DGEBS). De 1985 a 1988, o projecto foi apoiado pelo SNPRCN, mais tarde chamado de Instituto Nacional do Ambiente (INAMB). Nasceram, então, vários projectos de Educação Ambiental nas escolas básicas e secundárias, com o objectivo de criar nos jovens a sensibilidade para a defesa do ambiente. No primeiro ano, 1985/86, o Projecto integrou 4 escolas, no segundo ano alargou-se a 11 escolas e, ao longo do ano lectivo, passou a abranger 38, de diferentes níveis de ensino.

Estes projectos escolares procuravam a construção de uma interdisciplinaridade potencialmente transformadora de práticas e de relações educativas. Tentava assim cumprir-se o que se 
considerava ser a especificidade da Educação Ambiental e que constava do protocolo: "em relação a outras formas de educação, consiste no facto de ela ser orientada para a solução de problemas, ser obrigatoriamente interdisciplinar, integrar-se na comunidade e ter um carácter de educação permanente" (BENAVENTE, 1993, p.32).

Os objectivos do Projecto de Educação Ambiental para o Desenvolvimento, explícitos no relatório da DGEBS de 1986, desenvolviam-se em torno de três eixos: sensibilizar os professores e alunos para o problema do ambiente; possibilitar aos alunos uma melhor gestão dos espaços geográficos; testar a introdução da dimensão ambiental dos programas e ensaiar novas metodologias e novas estratégias de ensino-aprendizagem. Estes projectos escolares procuravam a construção de uma interdisciplinaridade potencialmente transformadora de práticas e de relações educativas, uma vez que (i) implicam aprendizagem holística e cooperativa, (ii) dizem respeito a problemas reais, (iii) relacionam diferentes tipos de conhecimento para resolver esses mesmos problemas, (iv) envolvem uma abordagem interdisciplinar, (v) valorizam actividades de outdoor, (vi) abrem a escola à comunidade, (vii) alteram valores sociais dominantes. E, embora impliquem bastante tempo, são um processo de aprendizagem ao longo da vida.

As escolas envolvidas foram desenvolvendo projectos de EA. Alguns, mais restritos, eram realizados dentro da própria escola, com foco, por exemplo, em criação de hortas pedagógicas, reciclagem de papel e compostagem de lixos domésticos. Outros desenvolveram-se sob a forma de projecto interdisciplinar, saindo da escola e tomando a forma de projecto comunitário, com foco em estudos da cidade, de lixeiras, de rios poluídos, alertando para os perigos de saúde pública. Outros ainda tomaram um carácter internacional, com intercâmbio de experiências ligadas ao ambiente em vários países.

Hoje existe, em Portugal, um Ministério do Ambiente, do Ordenamento do Território e do Desenvolvimento Regional (http://www.portugal.gov.pt/Portal/PT), o Instituto da Conservação da natureza (http://www.icn.pt/), há sítios na Internet relacionados com EA (http://www.aspea.org/), há sítios escolares de âmbito nacional e internacional 
(http://web.educom.pt/escolovar/ambiente floresta.htm). Há também vários grupos ambientalistas, como a Quercus (http://www.quercus.sensocomum.pt/), a liga para a protecção da Natureza (http://www.lpn.pt/) e todo um trabalho de protecção da natureza e de criação de parques e reservas naturais.

\section{Linhas de Investigação em Educação Ambiental: A Visibilidade de Boas Práticas}

Os pressupostos de fundamentação metodológica de investigação baseiam-se no Interaccionismo Simbólico na tradição de Mead, Blumer e Becker (WOODS, 1979) e assentam em três postulados: os seres humanos agem em direcção ao que tem significado para eles; a atribuição de significado aos objectos através de símbolos é um processo contínuo; e este processo tem lugar num contexto social. Assentam também na análise do discurso dos protagonistas que trazem as suas experiências à investigação, que dá, deste modo, importância aos acontecimentos a partir das perspectivas de quem os vive. Tem sentido neste contexto a filosofia da linguagem de Bakhtin (1981) na distinção que estabelece entre o discurso da autoridade e o discurso internamente persuasivo, a "decisiva significância na evolução da consciência individual, à medida que a pessoa distingue o seu próprio discurso do de outros, entre o seu próprio pensamento e o de outras pessoas" (BAKHTIN, 1981, p. 345). O discurso internamente persuasivo, para Bakhtin, está fortemente interligado com a "própria palavra", mesmo "pensamento próprio", e, na compreensão dialógica da linguagem, este discurso é metade nosso e metade de outra pessoa, construindo-se sobre elementos de discursos de autoridade. Ao dar atenção ao discurso do outro, estamos a valorizar a sua esfera privada. Segundo Oliveira-Martins (1991, p. 43):

Não como fundamento egoísta, mas como base do respeito mútuo (...) podemos ir do indivíduo ao cidadão e à cidadania e destes à esfera pessoal de cada um dos componentes da comunidade humana - esfera onde se encontram vocações e valores, desígnios e projectos, numa palavra, o que nos une e nos separa, o que é comum e o que o distingue, o público, o social e o privado. 
Tendo em conta estes pressupostos, as linhas de pesquisa que melhor se adequam à Educação Ambiental são a etnografia, o estudo de caso, a investigação-acção, em que a narrativa pode assumir um carácter quer de investigação como método, quer de relato que traz as vozes e o discurso a ser analisado. Há nestas linhas de investigação um objectivo comum: dar visibilidade a projectos inovadores, perceber dinâmicas, formas de implementação, dificuldades e avaliação por quem viveu estes projectos.

\subsection{Etnografia e estudo de caso - um exemplo de uma investigação em Educação Ambiental}

Foi realizado em 1993 um estudo sobre o desenvolvimento de um projecto de Educação Ambiental numa escola portuguesa, a Escola Secundária de Benfica, em Lisboa. Seguiu-se uma metodologia com características etnográficas, tendo o relato tomado a configuração de um estudo de caso. Interessava-nos analisar um projecto que, em torno da Educação Ambiental, procurava melhorar a socialização e a aprendizagem dos alunos e, em particular, dos alunos com necessidades educativas especiais. $\mathrm{O}$ Projecto foi da iniciativa de algumas professoras da escola, coexistia com outros projectos, procurava afirmar o seu próprio espaço e conquistar meios para o seu desenvolvimento.

Com a investigação, apercebemo-nos das dificuldades de desenvolver projectos na escola, dos bloqueios que se vão encontrando e da multiplicidade de interacções e de aprendizagens a vários níveis. Sentimos na realidade o desajustamento com os nossos escritos teóricos e a grande dificuldade de dar conta da multiplicidade de aspectos passíveis de análise. Só a investigação que entra no mundo dos outros, os ouve, acompanha as suas acções e se aproxima das práticas é que pode contribuir para as divulgar.

A recolha de dados foi feita utilizando-se os seguintes instrumentos: 
- Entrevistas: à equipa de coordenação; aos professores envolvidos no projecto; aos alunos de três turmas envolvidas especialmente (do ensino regular); aos alunos do ensino especial envolvidos no projecto

- Questionário aos 258 alunos da escola envolvidos no projecto em geral

- Observação de aulas

- Entrevistas aos órgãos de gestão

- Recolha documental

Privilegiámos o diálogo com todos os protagonistas, fundamentalmente os professores, devolvendo-lhes os resultados parciais que íamos obtendo e proporcionando reuniões regulares com eles, em que discutimos questões metodológicas, práticas que se iam desenvolvendo com os alunos e dificuldades e resistências que os protagonistas iam encontrando. Foram construídos documentos que ajudaram à discussão do projecto, tendo, no final, sido escrito um livro (BENAVENTE, 1993) em que, por um lado, se descreve toda a investigação realizada e, por outro, se apresentam textos teóricos que ajudam a explicar as práticas.

Algumas questões trazidas pela investigação etnográfica ajudam a reflectir sobre a implementação de projectos na escola:

- A natureza de um projecto inovador: origem e protagonistas

- A apropriação pelos outros professores: o contágio e as resistências

- A avaliação: do processo e do produto

A atenção a estas questões permite criar mecanismos de maior sucesso na implementação de novas práticas, pela previsão de dificuldades, diminuindo resistências e criando uma dinâmica de envolvimento colectivo.

\subsection{Narrativa como processo e como discurso de investigação, alguns exemplos}

De acordo com Stephens (1992), uma narrativa constitui-se a partir da imbricação de três componentes: a) História - abrange as personagens envolvidas em determinados acontecimentos, num espaço e tempo determinados, e possibilita uma primeira 
interpretação do que é contado; b) Discurso - forma específica como qualquer história é apresentada; c) Significação - uma interpretação de segundo nível que o ouvinte/ leitor/ espectador obtém a partir do inter-relacionamento da história e do respectivo discurso. Connelly e Clandinin (1990) estabelecem uma diferença entre narrativa e história. O fenómeno constitui a história, enquanto o método que a investiga e a descreve se concretiza numa narrativa. Deste modo, para aqueles autores, narrativa é o estudo das diferentes maneiras como os seres humanos experienciam o mundo. Pode dizer-se que as pessoas têm histórias e contam histórias das suas vidas, enquanto o investigador que utiliza o método da narrativa as descreve e faz construção e reconstrução das histórias pessoais e sociais, de acordo com um modelo interpretativo dos acontecimentos (CARTER, 1993).

Assim, uma narrativa proporciona informação situada e avaliada do que se investiga, permitindo aceder:

- Ao pensamento experiencial do professor;

- Ao significado que dá às suas experiências;

- À avaliação de processos e de modos de actuar;

- Aos contextos vividos e em que se desenrolaram as acções.

Com a narrativa, podemos, assim, investigar concepções, práticas, conhecimento didáctico, significado de aprendizagens de formação, conhecimento de conteúdo.

Exemplo de uma narrativa de uma jovem professora ao reflectir sobre a dificuldade que, por vezes, os professores sentem em fazer com que os alunos aprendam (GALVÃO, 1998):

Ainda, há dias, durante uma visita de estudo, eu estava a beber um pacote de leite com chocolate e estava a falar com os meus alunos.

Quando acabei, dobrei o pacote todo, achatei o pacote completamente. Eles perguntaram: $A$ 'stora' faz isso?

Respondi: Faço! E estive a explicar-lhes por quê, que era para facilitar a arrumação dos lixos. Em minha casa nunca se deitava um pacote para o lixo sem ser achatado.

Eles ficaram interessadíssimos! Eu até pensei que há pontos da matéria que acho que são essenciais e, volta e meia, é uma distracção incrível, agora por uma coisa destas! Eu a explicar o que faço lá em casa e é uma atenção enorme! A transmissão simples que se faz de atitudes também é importante. 
Eu penso: Ouviram-me 20, mas basta um depois repetir ao longo da vida com a familia.

Esta pequena história é bastante iluminativa do tipo de pessoa que esta professora é: consciente, preocupada com o ambiente, atenta aos alunos e às suas aprendizagens, não se importando de partilhar experiências pessoais. Para esta professora, cada indivíduo é responsável pela educação dos outros e essa educação faz-se pelo comportamento, pela atitude pessoal, e não pelo sermão moralista para marcar uma posição de poder. É também uma atitude reflexiva, mesmo a partir de situações simples como esta, que a formação de professores pode promover. Utilizar esta narrativa numa sessão de formação pode criar um ambiente de partilha e reflexão em que cada um encontra o seu espaço e a sua própria experiência.

No processo da narrativa, incluem-se cinco níveis de representação (RIESSMAN, 1993) da experiência vivida: dar sentido, contar, transcrever, analisar e ler. E poder-se-ia ainda acrescentar interpretar, uma vez que quem lê, necessariamente, dá um novo sentido ao texto, de acordo com as suas vivências e referentes. Cada um destes níveis é, ao mesmo tempo, reducionista e expansionista. Os narradores escolhem partes significativas do todo, mas acrescentam-lhe outros elementos interpretativos. A questão principal que se põe ao investigador, tendo em conta estes níveis de representação, é como estruturar a narrativa para poder ser analisada e interpretada, ao mesmo tempo que forma um relato coerente e agradável para ser lido.

Existem vários métodos de análise das narrativas dos professores, fundamentando-se em modelos sociológicos e sociolinguísticos, psicológicos, literários e antropológicos. Modelos psicolinguísticos e sociolinguísticos, por exemplo, fornecem explicações, por vezes contrastantes, para os textos e os discursos. Enquanto os modelos psicolinguísticos explicam a produção da linguagem com referência às capacidades semânticas e sintácticas do narrador, os modelos sociolinguísticos tendem a explicar os textos com referência às interacções sociais e às acções do narrador. No campo da sociolinguística, a ênfase está na relação entre os membros da comunidade e as formas e funções da linguagem. A 
organização do discurso produzido pelas interacções sociais incide no próprio discurso e nas actividades que, em conjunto, constituem a vida diária.

Dentro dos modelos sociolinguísticos, Labov (1972/1982, apud GALVÃO, 2005) propõe uma estrutura de análise bastante pragmática que tem sido aplicada a narrativas em educação. Segundo este autor, as narrativas têm propriedades formais, cada uma com a sua função. Uma narrativa completa deve incluir seis elementos: um Resumo (Abstract — sumário da substância da narrativa), Orientação (Orientation - tempo, lugar, situação, participantes), Complicação da acção (Complication — sequência de acontecimentos), Avaliação (Evaluation — significado e sentido da acção, atitude do narrador), Resolução (Result - o que aconteceu, como foi resolvida a complicação) e Coda (Coda - termina a narrativa, voltando a perspectiva para o presente). Com este tipo de estrutura, um narrador constrói uma história a partir de uma experiência primária e interpreta o significado dos acontecimentos, revelando a avaliação que está implícita. Labov desenvolve, assim, uma análise formal baseada em padrões determinados que examinam as unidades estruturais invariantes e uma análise funcional que evidencia duas funções sociais da narrativa - a referencial e a avaliativa. A função referencial consiste em dar ao ouvinte informação através da recapitulação da experiência do narrador, na mesma ordem em que ocorreram os acontecimentos. Labov diz que todos os narradores avaliam as ocorrências, daí a importância da função avaliativa que consiste em dar à audiência o significado da narrativa que o próprio autor lhe dá. Este modelo pode ser complementado com outros, uma vez que é restrito a um encadeamento sequencial de discurso, deixando de fora o voltar atrás e as intenções de futuro (que fazem parte de um modelo literário de análise, por exemplo). Um dos complementos deste modelo de análise pode ser a recorrência a sinais léxicos que examinam as relações semânticas entre frases, de modo a estudar as estruturas de informação dos textos em termos de inferências do escritor e do leitor. Estas relações são geralmente assinaladas por palavras-chave num texto. 
Exemplos de narrativa, utilizando-se o modelo de Labov para análise do discurso (GALVÃO, 1998):

Narrativa 1

Fomos à praia, reunimos alguns seres vivos, organizámos um aquário com os seres vivos que apanhámos (Resumo)

Entretanto o "aquário" morreu, isto é, os peixes morreram todos (Complicação da Acção)

E a partir daí fizemos uma discussão sobre a culpabilidade, de quem é que foi a culpa porque os que eram do campo culpavam os piscitas (Resolução da acção)

Os piscitas são os que vivem nas zonas piscatórias e normalmente têm grandes discussões com os do campo que vivem da agricultura e não da pesca (Orientação)

Os piscitas diziam que tinha feito muito mau tempo, e fez de facto e a culpa também não era deles, porque não podiam ir à escola, e portanto gerou-se uma discussão (Resolução da Acção)

Chegámos à conclusão que, se calhar a nível do planeta é isso que se faz, cada um empurra as responsabilidades, quem está do lado da indústria é que tinha obrigação de tratar dela e não quem está no país ao lado, portanto as responsabilidades são sempre atiradas para os outros (Avaliação)

E eles perceberam isso (Coda)

\section{Narrativa 2}

Quando estava a dar as lixeiras eu queria fazer um esquema para mostrar o destino do lixo (Resumo)

Havia lixeiras, aterros, incineradoras, mas em vez de estar a escrever aquilo tudo, pedi a um aluno para ir desenhar um caixote do lixo (Complicação da Acção)

Então tinha um caixote do lixo com um gato a sair da tampa a dizer miau, depois fizemos setas e a partir das setas pusemos os vários destinos do lixo. Eles gostaram tanto do desenho do colega que fui inundada com desenhos da turma toda com caixotes do lixo com gatos lá dentro (Resolução da Acção)

Era o gato do Zezinho e isso também ficou a pertencer a esse ambiente de aula (Orientação)

Quando dei as teias alimentares (Complicação da Acção)

Fui buscar o exemplo do gato para eles perceberem o ciclo da matéria (Resolução da Acção)

Porque o Zezinho era o terrível da classe (Orientação)

E então eu dizia: “O gato do Zezinho morreu, foi para a terra, mas entretanto na terra transformou-se em sais minerais que vão para a alface. Depois o Zezinho come a alface e assim come o gato". E eles percebiam que era um ciclo e não paravam de fazer perguntas: - O quê, 
se ele for comer a alface está a comer os sais minerais do gato?" (Resolução da Acção)

Bem, eles riram-se imenso, porque era uma espécie de vingança (Orientação)

E diziam: "Os dinossáurios [sic] morreram há tanto tempo, foram para a terra e nós agora podemos ter elementos químicos dos dinossáurios? (Resolução da Acção)

Só vivido assim com exemplos reais é que eles vêem, por exemplo, como é que o ciclo da matéria funciona (Avaliação)

Nestas duas narrativas, fica bem em evidência, pelo modelo de análise, o que aconteceu e desencadeou todo o processo de aula, como a situação foi resolvida e que avaliação faz a professora dos acontecimentos e do seu papel. Na primeira narrativa, ficamos a saber que não interessa tanto encontrar as causas da morte dos peixes, mas explorar socialmente a culpabilização mútua dos alunos. Seres vivos retirados do seu ambiente natural morrem com muita frequência devido a razões bastante diversas, mas os alunos devem ter sentido, como é natural, que tinha havido negligência humana. A professora soube tirar bem o partido desta situação, transformando o objecto da discussão. Trata-se de uma chamada de atenção para a importância da análise dos factos e para a não acusação gratuita. Mostrou aos alunos que todos eram responsáveis pela manutenção das boas condições para a sobrevivência dos peixes, logo, todos tinham responsabilidade no que aconteceu. Ou talvez não, talvez se devesse a uma causa externa, mas isso precisava de ser melhor analisado. Acusarem-se mutuamente só fazia perder tempo. Em termos de Educação Ambiental, é um bom exemplo de envolvimento dos alunos numa experiência real vivida por todos. A avaliação da professora revela isto mesmo.

A segunda narrativa apresenta dois episódios distintos, constituindo histórias independentes, embora digam respeito à mesma situação educativa. A primeira história diz respeito ao apelo à criatividade dos alunos, de modo a envolvê-los afectivamente no assunto em estudo. A segunda vem testemunhar a utilização das vivências dos alunos que os ajudam a abordar e a compreender os fenómenos naturais. Neste caso, a utilização do gato do Zezinho funcionou como estímulo à abordagem do assunto e, simultaneamente, acompanhou o processo de transformação da matéria, numa interacção entre o científico e o senso comum. O 
aspecto lúdico que atravessa toda a explicação sobre o ciclo da matéria permanece em evidência numa situação diferente, a das lixeiras.

\section{A Educação Ambiental nos Currículos Escolares em Portugal}

Com a crescente importância da Educação Ambiental em Portugal, multiplicaram-se as iniciativas, de modo a tornar os jovens mais conscientes e participativos. Os currículos foram também sendo alterados de modo a corresponder a esta necessidade e hoje a Educação Ambiental é um assunto transversal ao longo de toda a escolaridade. No entanto, nos currículos de Ciências, a EA tem hoje grande expressão do $1^{\circ}$ ao $3^{\circ}$ ciclo do Ensino Básico (6-14 anos), patente no Currículo Nacional (DEB, 2001) e especialmente no de Ciências Físicas e Naturais (GALVÃO, 2002). Este currículo, desenvolvido em torno da Ciência, Tecnologia, Sociedade e Ambiente, decorre de 4 temas: Terra no Espaço, Terra em Transformação, Sustentabilidade na Terra e Viver Melhor na Terra. Cada um destes temas inicia-se com problemas que orientam conteúdos de Ciências Naturais e de Ciências Físico-Químicas que podem ser tratados de uma forma interdisciplinar. O tema Sustentabilidade, por exemplo, propõe que se inicie o seu estudo a partir de questões como as seguintes: Quais são as consequências das aplicações científicas e tecnológicas para a Terra? Quais são as consequências para a Terra da utilização desregrada dos recursos naturais? Como podemos contribuir para a sustentabilidade da Terra?

Estas questões podem levar ao estudo interdisciplinar da Gestão Sustentável dos Recursos, dando atenção à utilização dos recursos naturais e consequências de uma má utilização, à protecção e conservação da natureza e aos custos, benefícios e riscos das inovações científicas e tecnológicas. Nesta proposta, estão envolvidos os conceitos de Ciência, Tecnologia, Sociedade, Ambiente (CTS-A), de Literacia científica e de Sustentabilidade.

A Perspectiva CTS-A implica saber olhar inteligentemente para o que nos rodeia e, numa perspectiva de resolução de problemas, ultrapassar situações aparentemente insolúveis. É a possibilidade de análise do papel social da ciência e da tecnologia, 
tornando-as acessíveis aos cidadãos, e de aprendizagem social da participação pública em decisões relacionadas com os temas tecnológicos e científicos.

A Literacia Cientifica no currículo escolar implica ver o mundo como uma amálgama de pensamentos, acções, acontecimentos e artefactos que, de forma conectiva, compõem as culturas e as sociedades que partilhamos.

O conceito de Sustentabilidade ajuda-nos a compreender e a lidar estrategicamente com um conjunto de questões globais que dominam a cena internacional (mudança climática e crescimento populacional, por exemplo) e que não podem ser resolvidas por cada país independentemente como no passado. No entanto, reconhecem-se dificuldades na implementação destes conceitos, principalmente devido a: (i) Pressão da tradição (é difícil mudar práticas), (ii) Pressões políticas para obtenção de resultados imediatos (este modo de funcionar é um processo de longo prazo), (iii) Tensão entre a autonomia e a incerteza (a insegurança leva à manutenção do que se considera adquirido), (iv) Conceito abrangente de competência (definir aprendizagens dos alunos em termos de competências não é fácil de perceber) e (v) Avaliação de competências (avaliar competências não é o mesmo que avaliar apenas conteúdos, o que gera também dificuldades aos professores).

\section{Considerações Finais}

Mudar as práticas é um processo que exige tempo, disponibilidade e vontade. Não basta estar escrito nos currículos que determinadas estratégias são mais eficazes que outras, é necessário que os professores constatem os efeitos da interdisciplinaridade e das vantagens de ensinar num contexto compreensível para os alunos. Quando os assuntos a ensinar são novos, é legítimo que os professores sintam maior preocupação e se interroguem sobre quais as melhores estratégias para os fazer compreender aos alunos. A Sustentabilidade da Terra ou a relação CTS são assuntos actuais que exigem preparação e flexibilidade dos professores para serem bem geridos na aula, e não se podem 
ignorar hoje em dia, constituindo, além disso, temas que interessam aos jovens.

Consciência ambiental implica um questionamento profundo, um repensar a maneira de produzir, de consumir, de trabalhar, e um posicionamento perante a vida que integra a solidariedade para com as gerações futuras. Isto significa partilhar de ética que interpela os valores tradicionais, por vezes, maioritários, que têm expressão em crenças que posicionam o ser humano com todos os direitos. A vivência de projectos de Educação Ambiental coloca os alunos na abordagem global e interdisciplinar de problemas, permitindo-lhes compreender a importância dos valores de solidariedade, de cooperação e de justiça social, ajudando-os também a definir o seu lugar e papel na natureza.

As linhas de investigação aqui apresentadas permitem compreender melhor as inovações dos professores criativos, podendo contribuir para a divulgação dessas práticas. E algumas questões de investigação decorrentes são, por exemplo:

- Estarão os nossos alunos mais sensibilizados hoje para a protecção dos ecossistemas?

- Continuamos numa perspectiva antropocêntrica ou ecocêntrica de EA?

- Desenvolvimento sustentável é imperativo ou apenas moda?

- Que relação entre EA e cidadania?

\section{Referências bibliográficas}

ALMEIDA, A. Concepções ambientalistas dos professores: Suas implicações em Educação Ambiental. Dissertação de mestrado (policopiado). Lisboa: Universidade Aberta, 2005.

BAKHTIN, M. The dialogical imagination. Austin: University of Texas Press, 1981. 
BENAVENTE, A. (Coord.); CARVALHO, A.; GALVÃO, C.; LEÃO, C.; TAVARES, M. e CÉSAR, M. Mudar a escola, mudar as práticas. Um projecto de Educação Ambiental. Lisboa: Escolar Editora, 1993.

CARTER, K. The Place of Story in the Study of Teaching and Teacher Education. Educational Researcher, 22 (1), p. 5-12, 1993.

CONNELLY, M. e CLANDININ, J. Stories of Experience and Narrative Inquiry. Educational Researcher, 19 (5), p. 2-14, 1990.

DEB. Currículo nacional do ensino básico. Competências essenciais. Lisboa: Ministério da Educação, Departamento da Educação Básica, 2001.

GALVÃO, C. Professor: O início da prática profissional. Dissertação apresentada na Universidade de Lisboa para obtenção do grau de Doutor em Educação. Lisboa: Associação de Professores de Matemática (APM), 1998.

. Narrativas em Educação. Ciência \& Educação, 11 (2), p. 327-345, 2005.

(Coord.); NEVES, A.; FREIRE, A. M.; LOPES, A. M.; SANTOS, M. C.; VILELA, M. C.; OLIVEIRA, M. T. e PEREIRA, M. Ciências Físicas e Naturais. Orientações curriculares para o $3^{\circ}$ ciclo do ensino básico. Lisboa: Ministério da Educação, Departamento da Educação Básica, 2002.

OLIVEIRA-MARTINS, G. Escola de Cidadãos. Lisboa: Horizonte, 1991.

RIESSMAN, C. Narrative Analysis. California: SAGE, 1993.

STEPHENS, J. Language and ideology in children's literature. New York: Longman Publishing, 1992.

UNESCO. Réconcilier la sociosphère et la biosphère. Changements de l'environnement planétaire, métabolisme industriel, développement durable, vulnérabilité. Revue Internationale des Sciences Sociales, 121, 1989.

WOODS, P. The divided School. London: Routledge \& Kegan Paul, 1979. 